\title{
Time Matters: Framing Antismoking Messages Using Current Smokers' Preexisting Perceptions of Temporal Distance to Smoking-Related Health Risks
}

\author{
Kyongseok Kim and Hyang-Sook Kim \\ Department of Mass Communication \& Communication Studies, Towson University
}

\begin{abstract}
This study examined the effects of temporal framing used in messages about the future likelihood of developing smoking-related diseases on intention to quit smoking. Based on construal level theory (CLT), a causal model delineating the relationships among four variables - perceived temporal distance, personal relevance, perceived susceptibility, and behavioral intention-was proposed. The model was validated by an online experiment with a sample of 222 current smokers, revealing the effects of perceived temporal distance on behavioral intention via personal relevance and perceived susceptibility. Following the CLT-grounded model, the effects of different temporal frames (near future vs. distant future) on the four variables were tested. The near-future frame featured a risk perceived to be more temporally proximal (i.e., heart attack), and the distant-future frame featured a risk perceived to be more temporally distant (i.e., larynx cancer) among current smokers. Participants exposed to the near-future frame reported significantly shorter perceived temporal distance, greater personal relevance and perceived susceptibility to the risk portrayed in the message, and greater intention to quit smoking than participants exposed to the distant-future frame. Implications for antismoking communications are discussed.
\end{abstract}

Despite the steady decline in cigarette smoking rates in the United States over the past several decades (Centers for Disease Control and Prevention [CDC], 2015), nearly one out of five U.S. adults still smokes cigarettes, and more than half of them $(61.9 \%)$ are daily smokers (U.S. Department of Health and Human Services [USDHHS], 2014). In fact, cigarette smoking remains a major preventable cause of premature disease, and the risk of death from smoking-related health problems increased over the past 50 years across all populations (USDHHS, 2014), suggesting that using health communication to reduce the prevalence of cigarette smoking among current smokers is a daunting task.

Antismoking communication targeting current smokers has relied on threatening messages that depict health problems that could result from continued smoking (e.g., Beaudoin, 2002; Leshner, Bolls, \& Wise, 2011; Rogers, 1975; Ruiter, Kessels, Peters, \& Kok, 2014; Witte \& Allen, 2000). Fear appeals are the most common tactic used in threatening messages as "persuasive communication that attempts to arouse fear in order to promote precautionary motivation" (Ruiter et al., 2014, p. 65). According to Beaudoin (2002), more than onethird of television antismoking advertisements created between 1991 and 1999 (31\%) featured a threatening message. Also, the fear appeals used in these antismoking advertisements varied depending on the age of the intended recipient. For example, messages targeting youth and young adults tended to portray the short-term, imminent health consequences of smoking (e.g., gum disease), whereas messages targeting older adults were likely to present long- term, distant consequences (e.g., cancer) (e.g., Beaudoin, 2002).

However, whether these antismoking appeals can successfully evoke precautionary motivation to quit smoking remains inconclusive. Although youth and young adult smokers are likely to perceive the imminent 
health risks of smoking (e.g., gum disease) as personally relevant because they have social ramifications (e.g., yellow teeth are unattractive), the seriousness of smoking could be muted by placing greater emphasis on short-term consequences (Friedman, 1996; Goldman \& Glantz, 1998). On the other hand, older adult smokers are likely to recognize the seriousness of the long-term risks (e.g., cancer), but overemphasizing severe health consequences (e.g., death from cancer) could result in message avoidance, failing to elicit personal relevance (Ruiter et al., 2014). Accordingly, the challenge for health communicators is to design effective fear appeals that lead current smokers to feel

(a) that the antismoking message is personally relevant and

(b) that they are susceptible to the health risks presented.

Studies have shown that smokers tend to underestimate the likelihood of having smoking-related diseases (Dillard, McCaul, \& Klein, 2006; Weinstein, Marcus, \& Moser, 2005). This optimism makes current smokers less interested in quitting and, presumably, less susceptible to fear appeals using smoking-related health risks than former smokers and non-smokers. The optimism among current smokers can be attributed, at least in part, to the perceptions of temporal distance between the cause (cigarette smoking) and the effect (related health problem). Dillard et al. (2006) revealed that current smokers hold beliefs that smoking might not pose immediate, detrimental threats to health, such as "there is no risk if one only smokes for a few years" (p. 10). These findings suggest that effective antismoking communication should reduce perceived temporal distance to smoking-related health risks.

The current study sought to propose an antismoking communication strategy that might raise both perceived relevance and perceived susceptibility among current smokers by tapping into their preexisting perceptions of temporal distance to major smoking-related health risks. Current smokers were presumed to construe two smoking-related diseases (i.e., heart attack and larynx cancer) as having different degrees of temporality while still considering their health consequences to be equally serious. For example, a heart attack might be perceived as a relatively imminent risk (i.e., could happen in the near future) because it often occurs suddenly without accompanying long-lasting symptoms (National Institutes of Health [NIH], 2015), whereas larynx cancer might be perceived as a relatively distant risk (i.e., likely to occur in the distant future) because most cancers develop over time (NIH, 2007).

Based on construal level theory (CLT), which addresses the psychological distance that people subjectively experience about a future event (Trope \& Liberman, 2003), the current study posited that among current smokers, shorter perceived temporal distance to a smoking-related disease would lead to greater perceived personal relevance of the disease, in turn resulting in higher perceived susceptibility to the disease and greater intention to quit smoking. The following section discusses the general framework of CLT and a CLT-based causal model of antismoking communication that encompasses four variables: perceived temporal distance, personal relevance, perceived susceptibility, and behavioral intention.

\section{Literature review}

\section{Construal Level Theory (CLT)}

CLT is a social psychological theory that relates the psychological distance to a future event to one's mental representation of that event as a concrete or abstract idea (i.e., construal level) (Trope \& Liberman, 2010). The term psychological distance is defined as one's subjective perception of the temporal distance from the present to a future event; the term construal level refers to the mental process through which one represents an event (i.e., concrete or abstract) (Trope \& Liberman, 2003). For example, if a current smoker reads an antismoking message claiming that "people who smoke are more likely to have larynx cancer than people who don't smoke," psychological distance is the smoker's perception of how close or far the possible future occurrence of having larynx cancer is from the present, whereas construal level pertains to how concretely or abstractly the smoker mentally represents larynx cancer and its potential health consequences.

CLT postulates that people tend to construe future events perceived to be far from the present (distant-future events) in a relatively abstract manner and future events perceived to be close to the present (near-future events) in a relatively concrete manner (Liberman, Sagristano, \& Trope, 2002). Abstract construals are mental representations of the general, simple, but essential (i.e., high-order) characteristics of distant-future events, 
whereas concrete construals are representations of the specific, detailed, and contextual (i.e., low-order) features of near-future events (Trope \& Liberman, 2003). In the context of the current study, this difference in construal level suggests that if a current smoker perceives a smoking-related disease as a distant-future risk (e.g., larynx cancer), the smoker is more likely to construe the general health consequences of the disease (e.g., death); however, if a smoker perceives a disease as a near-future risk (e.g., heart attack), the smoker is more likely to construe the specific symptoms of the disease (e.g., chest pain and shortness of breath) (NIH, 2015).

\section{Importance of the temporality of health risks in antismoking messages}

While little research has been done to understand the role of individuals' perceived temporal distance to various smoking- related diseases in antismoking message effectiveness, two recent studies are notable. Nan, Zhao, Yang, and Iles (2015) tested the effects of different temporal frames in a cigarette warning label on message evaluation, attitude toward smoking, and intention to smoke among nonsmokers. Following the framework of CLT, the study presumed that in response to a near-future frame (e.g., one cigarette might cause immediate damage to the back of the eye), compared to a distant-future frame (e.g., smoking causes long-term damage to the back of the eye), individuals would construe the health problem more concretely, thus perceiving it as a more imminent risk (Chandran \& Menon, 2004; Trope \& Liberman, 2000). However, they found no significant main effects of temporal framing on the dependent variables. Instead, they speculated that the nonsmokers considered both the short-term and long-term health consequences of smoking depicted in the warning label to be personally irrelevant.

Employing a sample of smokers and nonsmokers and the same temporal framing manipulation used by Nan et al. (2015), Zhao, Nan, Iles, and Yang (2015) examined the moderating role of one's consideration of future consequences (CFC) - an individual difference variable related to being relatively more present oriented or future oriented (Strathman, Gleicher, Boninger, \& Edwards, 1994) - in the effect of temporal framing on multiple dependent variables, including attitude toward smoking. The study found that near-future framing elicited more negative attitudes toward smoking among low-CFC (i.e., present-oriented) individuals, whereas distant-future framing led to more positive attitudes among high-CFC (i.e., future-oriented) individuals. However, this matching effect between temporal framing and CFC was more evident for nonsmokers than smokers, and the main effects of temporal framing on the dependent variables were not clearly demonstrated for either group.

Because Nan et al. (2015) and Zhao et al. (2015) did not demonstrate the effectiveness of temporal framing per se, revisiting the nature of frames is necessary to help explain their findings. Both studies selected three smoking-related health problems relevant to the college student population (i.e., eye damage, skin aging, and impotence), each of which was framed as both a near-future risk (e.g., smoking might cause immediate damage to the eyes) and a distant-future risk (e.g., smoking might cause long-term damage to the eyes) for experimental purposes. However, if one has a preexisting perception of a disease in terms of its temporality (e.g., eye damage as a long-term health consequence of smoking), amessage frame that is inconsistent with that perception could be neglected or avoided and, thus, fail to elicit the desired attitudinal and/or intentional outcomes.

Research in cognitive and brain science suggests that a frame (i.e., a cognitive structure used while thinking) is established and stored in neural circuits in the brain by being repeatedly activated and, thus, strengthened (Lakoff, 2004). This approach to frames implies that changing preexisting frames simply by means of external input (e.g., words) is generally difficult, as indirectly suggested by the findings in Nan et al. (2015) and Zhao et al. (2015). However, when the external input is congruent with an "existing system of frames" (Lakoff, 2010, p. 72), it can activate the desired frame already stored in the brain. In communication research, framing is similarly defined as a mode of presenting information "in a way that resonates with existing underlying schemas" among audiences (Scheufele \& Tewksbury, 2007, p. 11). Therefore, antismoking messages are more likely to influence current smokers when health risks are temporally framed to match preexisting perceptions of temporal distance.

\section{Proposed model and hypotheses}

Instead of framing the same health problem as a near-future risk and a distant-future risk in antismoking message conditions, the current study used two different health problems and incorporated disease severity. Health message processing models, such as the Extended Parallel Processing Model (EPPM), assume that for 
a message to be effective, areasonable amount of fear aroused by perceived severity of the health risk presented in the message must precede message appraisal (Witte, 1992, 1994). The assumption in the current study was that current smokers would perceive the two smoking-related diseases to have temporal distances of different length but health consequences of equal severity (see Figure 1).

Four hypotheses were formulated. H1-H3 addressed the validity of a CLT-based model in the context of antismoking communication - that is, a health risk perceived to have near-future consequences, presumably construed concretely, should lead to higher personal relevance and perceived susceptibility to the risk and, in turn, to greater intention to quit smoking (see Figure 2). Following the theoretical model, H4 addressed the effects of two versions of an antismoking message, one containing a description of a relatively proximal health risk (i.e., heart attack) and the other containing a description of a relatively distant health risk (i.e., larynx cancer) on perceived temporal distance, personal relevance, perceived susceptibility to the risk, and intention to quit among current smokers.

Relationships among perceived temporal distance, personal relevance, perceived susceptibility, and intention

The framework of CLT suggests that a smoking-related disease perceived as temporally proximal (e.g., heart attack) is likely to be construed concretely with detailed mental imagery of specific instances (Trope \& Liberman,

Perceived Temporal Distance

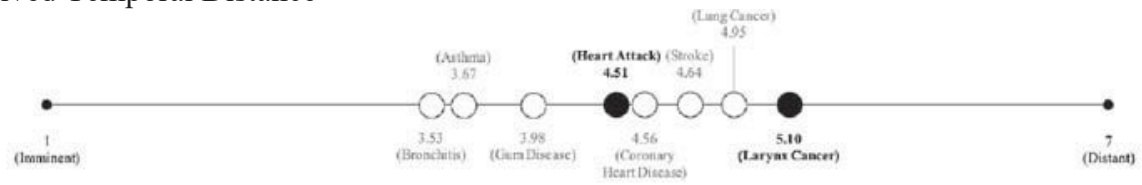

Perceived Severity

How serious do you think the consequences of the health problems listed below are?

$(1=$ not serious at all vs. 7 = very serious $)$

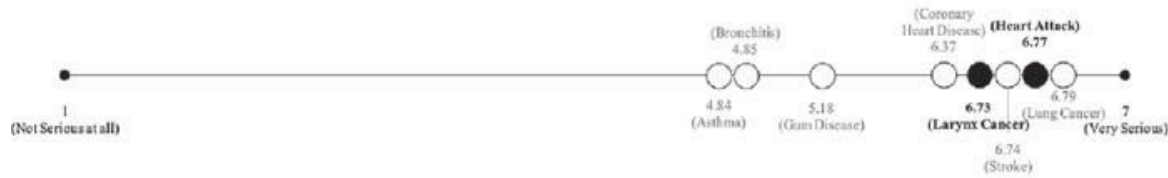

Perceived Likelihood

How likely do you think smoking will lead to an increased risk of the health problems listed below? (1 = very unlikely vs. 7 = very likely)

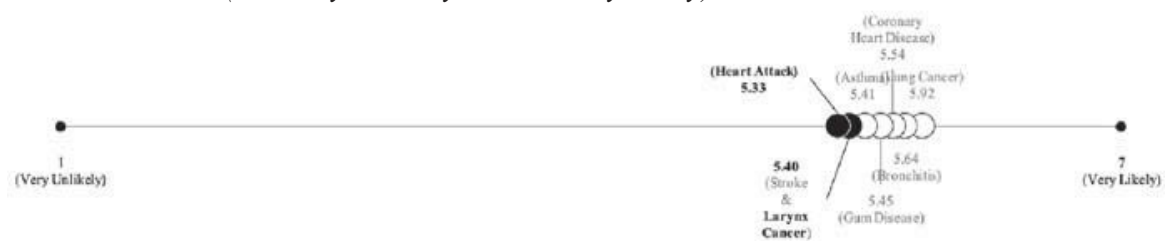

How imminent or distant do you think the likelihood is of the health problems listed

below happening to current smokers? $(1=$ imminent vs. $7=$ distant $)$

Figure 1. Pretest 1 results. Significant difference found between heart attack and larynx cancer in perceived temporal distance, $t(90)=$ $4.07, p<.001$. No significant differences found between heart attack and larynx cancer in perceived severity, $t(90)=.94, p=.35$, and perceived likelihood, $t(90)=.67, p=.49$. 


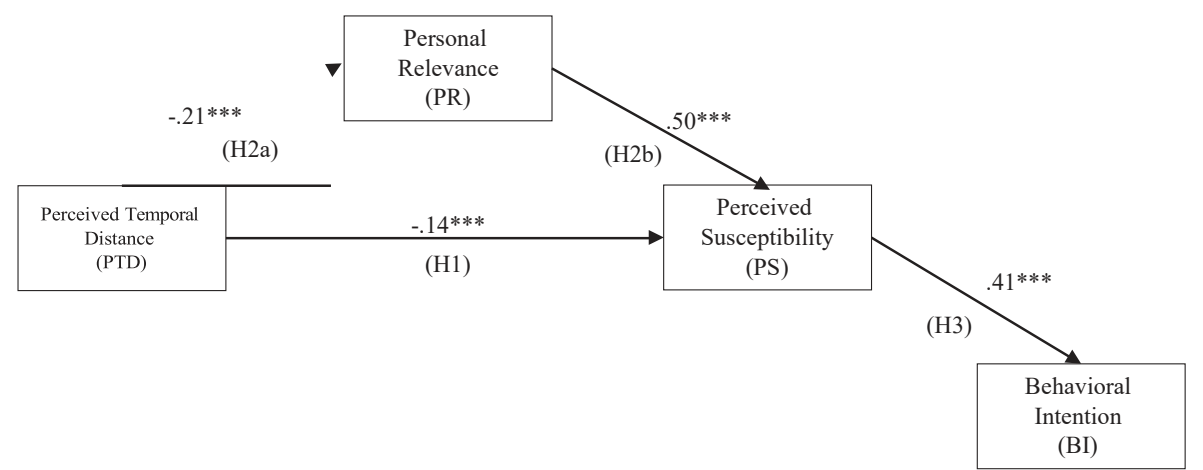

Figure 2. Proposed CLT-based model of antismoking communication. Path coefficient statistically significant at $* * * p<.001$. Model fit indices including $\chi^{2}=17.99, d f=2, \mathrm{CFI}=.90, \mathrm{TLI}=.69, \mathrm{RMSEA}=.19$.

2003), such as related symptoms (e.g., chest pain) and possible circumstances (e.g., a person grabbing his chest with pain). Research indicates that vivid mental representations of specific instances can lead to the belief that those instances are general phenomena (Zillmann, 1999), arousing feelings of personal vulnerability (Staple \& Velthuijsen, 1996). This CLT-based prediction-i.e., one's concrete construal of a near-future disease could result in an increased susceptibility to the disease - is in line with risk amplification (Slovic et al., 1991). Risk amplification is the process by which the real-world occurrence of an adverse event (i.e., an actual incident as opposed to one's abstract knowledge of potential harm), though it might be a minor incident, tends to evoke vivid mental imagery and increase the perceived magnitude of the risk. Accordingly, a current smoker who perceives a health risk as temporally closer is more likely to feel susceptible to the risk:

H1: Reduced perceived temporal distance to a health risk of smoking will lead to higher perceived susceptibility to the risk.

For the hypothesized relationship between perceived temporal distance and perceived susceptibility (H1), also worth scrutinizing is a possible psychological mechanism that mediates these two nodes of cognitive processing. Scholars in cognitive science have documented a meaningful relationship between mental imagery and personal relevance (e.g., Conway, Meares, \& Standart, 2004; D’Argembeau \& van der Linden, 2006). For instance, D'Argembeau and van der Linden (2006) found that when thinking about a future event, subjects who had vivid mental imagery of the event were more likely to perceive it as intense and personally important than those who had less vivid imagery. Along with the framework of CLT, these findings suggest that concrete construals of a near-future smoking-related health risk will result in higher personal relevance to the risk.

Traditional theories of fear appeal in health information processing (for a comprehensive review, see Witte, 1992) generally postulate personal relevance as a major antecedent of message effectiveness. That is, perceptions of fear and susceptibility are aroused only when a health message presents a threat perceived to be relevant to the recipient. Moreover, the literature of cognitive information processing has documented the effects of personal relevance on message elaboration and acceptance (e.g., Petty \& Cacioppo, 1986). In other words, as the recipient considers the issue presented in the message to be more personally relevant, he is more likely to attend to the message and to be persuaded - that is, in the context of this study, to feel more susceptible to the smoking-related health risk.

The current study anticipated that the influence of perceived temporal distance to the health risk on perceived susceptibility would be mediated by the perception of personal relevance:

H2a: Reduced perceived temporal distance to a health risk of smoking will lead to higher personal relevance to the risk.

H2b: Higher personal relevance to the health risk of smoking will lead to higher perceived susceptibility to the risk. 
In the framework of EPPM, perceived susceptibility to the health risk presented in the message plays a critical role in encouraging the recipient to comply with the health behavior suggested in the message (e.g., quitting smoking) (Krieger \& Sarge, 2013; Witte, 1992). If a current smoker feels vulnerable to the health risk, he is likely to be motivated to lower that vulnerability by trying to quit smoking:

H3: Higher perceived susceptibility to the health risk of smoking will lead to a greater intention to quit smoking.

\section{Health message effects}

The current study assumed the existence of established cognitions regarding the temporal distance to various smoking-related health risks and that people generally perceive some of the risks (e.g., heart attack) as more imminent than others (e.g., larynx cancer). A CLT-based model $(\mathrm{H} 1-\mathrm{H} 3)$ was proposed as a psychological mechanism through which the manipulation of the health message might affect perceived temporal distance, personal relevance, perceived susceptibility, and behavioral intention. In particular, the model suggests that in order to increase intention to quit smoking among current smokers, a message should raise both their perceived relevance and susceptibility by presenting a temporally proximal risk that is congruent with the recipient's preexisting perceptions of temporal distance. Based on the model, this study predicted that an antismoking message featuring a relatively proximal risk would be more effective than a message featuring a relatively distant risk:

H4: In response to an antismoking message depicting a proximal health risk (heart attack), compared to a message depicting a distant risk (larynx cancer), current smokers will report (H4a) shorter perceived temporal distance, $(\mathrm{H} 4 \mathrm{~b})$ higher personal relevance, $(\mathrm{H} 4 \mathrm{c})$ higher perceived susceptibility regarding the risk, and (H4d) greater intentions to quit smoking.

\section{Method}

\section{Participants}

A sample of 228 current smokers was initially obtained via Amazon Mechanical Turk (MTurk), a crowd-sourcing Internet marketplace that enables social scientific researchers to collect data from human subjects (Amazon Mechanical Turk, 2015). Six participants were excluded from the sample because they were not able to recall the stimulus antismoking message accurately. Past studies indicate that MTurk can provide researchers with more demographically diverse and reliable samples than traditional convenience samples of students (e.g., Buhrmester, Kwang, \& Gosling, 2011). A qualification requirement was set via MTurk to limit participants to individuals residing in the United States. A screening procedure also asked participants to describe a random image to verify their English proficiency (i.e., the image annotation test; Rashtchian, Young, Hodosh, \& Hockenmaier, 2010).

The average age of the participants $(N=222)$ was 36.2 years at the time of data collection $($ Min $=20.0$, Max $=$ $76.0, S D=11.90)$, and $59.5 \%(n=132)$ of them were male, whereas $40.5 \%(n=90)$ were female. A majority were White $(74.5 \%, n=165)$, followed by Asian $(12.2 \%, n=27)$, Hispanic $(8.1 \%, n=18)$, Black $(4.1 \%, n=$ 9), and others (e.g., mixed; $1.4 \%, n=3$ ). All of the participants had smoked at least once in the 30 days prior to data collection, and $87.8 \%(n=195)$ were daily smokers who had smoked every day of the previous month (Berg et al., 2012). On average, the participants smoked 10.65 cigarettes per day $(S D=7.66)$.

\section{Design and procedure}

A two-group (between-subjects), post-test-only design was used to determine the effects of message type (proximal risk vs. distant risk) on current smokers' perceived temporal distance, personal relevance, and perceived susceptibility to the health risk presented in the message and their intentions to quit smoking. After the participants were randomly assigned to one of the two message conditions, they were first asked to report their smoking frequency (Berg et al., 2012) and general knowledge about smoking-related health risks (CDC, 2015). Then, the participants were exposed to a stimulus antismoking message and responded to the items measuring the four dependent variables. Finally, they responded to the demographic questions. The participants received a monetary reward after completing the online experiment. 


\section{Manipulation and stimulus materials}

Perceived temporal distance to a smoking-related health risk was manipulated by presenting an antismoking message portraying either a temporally proximal risk or a temporally distant risk of smoking. The proximal and distant risks were designed to be congruent with people's general, preexisting perceptions of temporal distance. To raise message effectiveness, both the proximal and the distant risks were designed to be perceived as highly and equally severe (Peters, Ruiter, \& Kok, 2013).

\section{Manipulation check}

A pretest was conducted using a sample of 91 individuals (who did not participate in the main experiment) to determine their pre-existing perceptions of the temporal distance and severity of eight potential health consequences of smoking: asthma, bronchitis, coronary heart disease, gum disease, heart attack, larynx cancer, lung cancer, and stroke (CDC, 2016). Perceived temporal distance and severity were measured by asking, "How imminent or distant do you think the likelihood is of the health problem occurring to current smokers?" $(1=$ very imminent vs. 7 = very distant $)$ and "How serious do you think the health consequences of the problem are?" $(1=$ not serious at all vs. 7 = very serious), respectively.

Among the potential health consequences considered most severe-heart attack, larynx cancer, lung cancer, and stroke - the biggest difference in perceived temporal distance was observed between heart attack $\left(M_{\text {Heart }}\right.$ Attack $=4.51, S D=1.68)$ and larynx cancer $\left(M_{\text {Larynx Cancer }}=5.10, S D=1.38\right)$, and the difference was statistically significant $(t[90]=4.07, p<.001)$. The two health risks were also perceived as highly and equally severe $\left(M_{\text {Heart Attack }}=6.77, S D=.50\right.$ vs. $\left.M_{\text {Larynx Cancer }}=6.73, S D=.56, t[90]=.94, p=.35\right)$.

Additionally, the participants were asked to indicate their perceptions of the likelihood that smoking would lead to an increased risk of having the health problems listed above. No significant difference in the participants' perceived likelihood was found between heart attack $\left(M_{\text {Heart Attack }}=5.33, S D=1.43\right)$ and larynx cancer $\left(M_{\text {Larynx Cancer }}=5.40, S D=1.44, t[90]=.67, p=.49\right)$. Accordingly, heart attack was chosen as a relatively proximal risk and larynx cancer as a relatively distant risk for the stimulus antismoking messages. Figure 1 summarizes the pretest results.

\section{Confound check}

Two stimulus antismoking messages were created in the form of a public service announcement (PSA) endorsed by the CDC. Except for disease type (heart attack or larynx cancer), the two stimuli were identical in form and content. ${ }^{1}$ Another pretest was conducted as a confound check using a sample of 33 individuals (who did not participate in the main experiment). They were asked to evaluate the formal features of the two messages (e.g., visual quality) and the credibility of the source (i.e., the CDC). A 3-item, 7-point scale of attitude toward the PSA (e.g., "Please rate the PSA you just saw focusing on its formal features rather than the claim it makes," 1 = bad vs. 7 = good; MacKenzie \& Lutz, 1989) and a 4-item, 7-point scale of source credibility (e.g., "The CDC makes truthful claims," 1 = strongly disagree vs. 7 = strongly agree; Sinclair \& Irani, 2005) were used.

The pretest revealed not significant differences between the two stimuli in attitude toward the PSA ( $M_{\text {Heart Attack }}$ $=5.55, S D=1.40$ vs. $\left.M_{\text {Larynx Cancer }}=5.35, S D=1.15, t[31]=.43, p=.67\right)$ or perceived source credibility $\left(M_{\text {Heart Attack }}=6.00, S D=.71\right.$ vs. $M_{\text {Larynx }}$ Cancer $\left.=6.17, S D=.95, \mathrm{t}[31]=.59, p=.56\right)$. The results suggest that message evaluations would not be confounded by perceptions of the formal message features or the source.

\section{Dependent variables}

Four dependent variables were used to assess the effects of the two stimulus antismoking messages.

\section{Perceived temporal distance}

\footnotetext{
${ }^{1}$ The stimuli are available from the corresponding author upon request.
} 
An item adopted from Ji, Guo, Zhang, and Messervey (2009) was used to measure participants' perceived temporal distance to heart attack and larynx cancer: "How temporally imminent or distant do you think the likelihood is of a heart attack (or larynx cancer) happening to you?" $(1=$ very imminent vs. $7=$ very distant) $(M=4.26, S D=1.63)$.

\section{Personal relevance}

Participants' perceptions of relevance of the health risk presented in the message were measured using a 3item, 7-point scale adapted from Zaichkowsky (1985): "To me, the health problem depicted in the PSA is. .." $(1=$ irrelevant/of no concern/doesn't matter vs. $7=$ relevant/of concern/matters $)(M=5.69, S D=1.18, a=$ $.99)$.

\section{Perceived susceptibility}

A 3-item, 7-point scale was adopted from the Risk Behavior Diagnosis Scale of Witte, Cameron, McKeon, and Berkowitz (1996) to assess participants' perceptions of susceptibility to the health risk presented in the message: "I think I am at risk for a heart attack (or larynx cancer)," "I think it is possible that I will have a heart attack (or get larynx cancer)," and "I think I am susceptible to a heart attack (or larynx cancer)" ( 1 = strongly disagree vs. 7 = strongly agree $)(M=5.20, S D=1.09, a=1.00)$.

\section{Intention to quit}

Participants' intentions to quit smoking were measured using a 2-item, 7-point scale adopted from Kim, Bigman, Leader, Lerman, and Cappella (2012): "How likely will you try to quit smoking in the next six months?" and "How likely will you quit smoking in the next six months?" $(1=$ will definitely not vs. $7=$ definitely will $)(M=4.45, S D=2.06, a=.97)$.

\section{Control variables}

The effects of the stimulus health message on the four dependent variables were assessed while controlling for three known factors (i.e., age, smoking frequency, and knowledge about smoking-related health risks) that could influence participants' perceived temporal distance (age; Von Wagner, Semmler, Power, \& Good, 2010), personal relevance (smoking frequency; Petty \& Cacioppo, 1986), and perceived susceptibility (knowledge; Evans et al., 1978). Smoking knowledge was measured by asking how informed participants were about the potential causal link between smoking and the health problem (heart attack or larynx cancer).

\section{Results}

\section{Structural relations between perceived temporal distance, personal relevance, perceived} susceptibility, and behavioral intention (H1-H3)

$\mathrm{H} 1-\mathrm{H} 3$ addressed the validity of the proposed CLT-based model of antismoking communication. The hypotheses were tested through path analysis using the pooled data $(N=222)$. As a manipulation check, message type was confirmed to produce significant variability in perceived temporal distance. The strong, negative coefficient for the path from the manipulation to perceived temporal distance $(b=-.71, \mathrm{SE}=.21, p$ $<.001$ ) indicated that participants' perceived temporal distance decreased in response to the message portraying a relatively proximal risk (i.e., heart attack, dummy coded as 1) and increased in response to the one portraying a relatively distant risk (i.e., larynx cancer, dummy coded as 0). The path analysis was conducted while controlling for age, smoking frequency, and knowledge about the potential health consequences of smoking. The full model is presented in the Appendix.

The results of the path analysis supported the hypothesized relationships among perceived temporal distance (PTD), personal relevance (PR), perceived susceptibility (PS), and behavioral intention (BI); all path coefficients were significant at $p<.001$ (see Figure 2). As expected, PTD had significant negative effects on $\mathrm{PS}(\mathrm{H} 1: b=-.14, \mathrm{SE}=.04, p<.001)$ and $\mathrm{PR}(\mathrm{H} 2 \mathrm{a}: b=-.22, \mathrm{SE}=.05, p<.001)$. Also, $\mathrm{PR}$ had a significant positive effect on PS (H2b: $b=.50, \mathrm{SE}=.05, p<.001)$, and PS had a significant positive effect on BI (H3: $b$ $=.41, \mathrm{SE}=.12, p<.001)$. Therefore, hypotheses 1,2 , and 3 were supported. 


\section{Message effects (H4)}

Hypothesis 4 predicted that the message depicting a relatively proximal risk of smoking (i.e., heart attack) would be more effective than the message portraying a relatively distant risk (i.e., larynx cancer), thereby resulting in shorter PTD (H4a), higher PR (H4b), higher PS (H4c), and greater BI (H4d).

Given the conceptual relationships among the four dependent variables (see H1-H3), a multivariate analysis of covariance (MANCOVA) was conducted with the independent variable of message type. Age, smoking frequency, and knowledge about smoking-related health risks were entered into the analysis as covariates.

Significant main effects of message type on the four dependent variables were found at both the multivariate ( $F$ for Wilks' $\lambda=12.96, p<.001, \eta^{2}=.20$ ) and univariate levels. As predicted, participants who received the message depicting the risk of having a heart attack, compared to those who received the message describing the risk of developing larynx cancer, reported significantly shorter PTD $\left(M_{\text {Heart Attack }}=3.92, S D=1.22\right.$ vs. $\left.M_{\text {Larynx Cancer }}=4.59, S D=1.90, F[1,217]=10.88, p<01[.001], \eta^{2}=.05\right)$, higher PR $\left(M_{\text {Heart Attack }}=6.08, S D\right.$ $=1.11$ vs. $\left.M_{\text {Larynx Cancer }}=5.31, S D=1.12, F[1,217]=49.73, p<001, \eta^{2}=.19\right)$, higher PS $\left(M_{\text {Heart Attack }}=5.41\right.$, $S D=.78$ vs. $\left.M_{\text {Larynx Cancer }}=4.99, S D=1.29, F[1,217]=15.84, p<001, \eta^{2}=.07\right)$, and greater BI $\left(M_{\text {Heart Attack }}\right.$ $=4.84, S D=1.86$ vs. $\left.M_{\text {Larynx Cancer }}=4.07, S D=2.19, F[1,217]=4.91, p<05[.03], \eta^{2}=.02\right)$. Therefore, hypothesis 4 was supported.

\section{Discussion}

Previous studies have suggested that current smokers were hardly swayed by antismoking messages using fear appeals (e.g., Wolburg, 2006), a trend that poses significant challenges to health professionals who strive to reduce smoking (Myers, 2014). The failure of fear appeal messages targeting current smokers can be attributed to at least one of the following reasons: (a) the health risks portrayed in the messages might not be perceived as severe enough to elicit perceptions of susceptibility (e.g., gum disease); (b) the severe health consequences depicted in the messages might not be perceived as personally relevant (e.g., death); and (c) current smokers might be generally optimistic about their likelihood of suffering from smoking-related diseases in the near future (Goldman \& Glantz, 1998; Ruiter et al., 2014; Weinstein et al., 2005).

The findings of the current study show that current smokers' perceptions of susceptibility and relevance to smoking-related health risks could be significantly raised by reducing their perceived temporal distance to the risks. The parsimonious CLT-based model proposed in this study indicates that as current smokers perceived a smoking-related health risk as more temporally proximal - presumably, their perceived proximity to the risk might encourage them to construe the risk with more vivid and concrete imagery - they reported higher levels of perceived susceptibility and relevance to the risk. Also, the heightened perceptions of susceptibility resulted in greater intentions to quit smoking.

The findings also suggest that designing a more effective temporal frame requires more knowledge about the preexisting perceptions of temporal distance to various smoking-related health problems the current smokers hold. Two recent studies (Nan et al., 2015; Zhao et al., 2015) tested the effects of temporal framing on cognitive, attitudinal, and behavioral outcomes by manipulating the temporality (i.e., near future vs . distant future) of a smoking-related health problem (e.g., eye damage) in a cigarette warning label, but evidence that the temporal framing was effective did not emerge.

According to research in cognitive and brain science and communication, frames are entrenched in the brain and are generally difficult to change using external input in the form of words (Lakoff, 2004; Scheufele \& Tewksbury, 2007). Thus, temporal framing should attempt to activate preexisting frames rather than attempt to alter them. People might have established perceptions of the temporal distance of various smoking-related diseases over time, perhaps having directly or indirectly experienced their consequences or having been exposed to media reports that some diseases are acute, having a sudden and immediate onset, and that others are chronically progressive, becoming serious in the relatively distant future. The present study demonstrated that current smokers indeed tended to perceive some health risks (e.g., heart attack) as more temporally proximal than others (e.g., larynx cancer), despite considering the health risks equally severe, and that those perceptions influenced how they interpreted the anti-smoking messages. 


\section{Perceived temporal distance as a driver of cognitive heuristics and message elaboration}

The CLT-based model proposed in this study showed that decreased perceived temporal distance to a smokingrelated health risk both directly $(\mathrm{H} 1)$ and indirectly via personal relevance $(\mathrm{H} 2 \mathrm{a} \& \mathrm{H} 2 \mathrm{~b})$ increased perceived susceptibility. From the perspective of information processing, these findings imply that vivid and concrete construals of the health risk presented in the message might have brought about heuristic and systematic processing of the message (Chaiken, Liberman, \& Eagly, 1989).

Previous studies have identified emotions (e.g., fear) as a source of cognitive heuristics (i.e., readily accessible mental resources for cognitive evaluation; Chaiken, 1987) (e.g., Dillard, Plotnick, Godbold, Freimuth, \& Edgar, 1996). That is, if current smokers experienced feelings of fear due to vivid mental imagery in response to a message portraying the proximal health risk of a heart attack, those feelings could automatically elicit heightened perceptions of susceptibility to the risk. Additionally, current smokers' proximal perceptions of the risk can yield greater personal relevance, confirming previous CLT-based studies (e.g., Fujita, Eyal, Chaiken, Trope, \& Liberman, 2008). In fact, persuasion research on the impact of temporal information on attitude has tended to manipulate the level of personal relevance by varying temporal distance. In Petty, Cacioppo, and Goldman (1981), for example, the level of personal relevance was operationalized by informing participants that their university would adopt senior comprehensive exams in 1 year (high) or in a decade (low). In a sense, personal relevance might be considered a form of psychological distance. ${ }^{2}$ Heightened personal relevance can in turn motivate more systematic message processing, which can in turn result in greater message acceptance (e.g., feeling more susceptible to the proximal smoking-related health risk presented in the message). In sum, perceived proximity to the risk could lead to simultaneous heuristic and systematic message processing, increasing message effectiveness.

The above interpretation regarding the dual processing of the near-future frame is in line with two ways that people perceive risk in response to communication stimuli: risk as feelings and risk as analysis (Slovic, Finucane, Peters, \& MacGregor, 2004, 2005). Risk as feelings is also known as the affective heuristic, through which people automatically (or preconsciously) generate a negative affective response to a communication stimulus (e.g., the words "heart attack") (Slovic et al., 2004). This automatic, affective response is facilitated through repeated associations between experience and emotion (Zajonc, 1980) and helps people quickly construe a stimulus as a concrete image and effectively navigate the world (Slovic et al., 2004). In contrast, risk as analysis is also known as the analytic system, which is a relatively more effortful and conscious evaluation of a stimulus - especially when the stimulus has personal significance - and is oriented toward a delayed event. These two types of risk perception suggest that a message portraying a proximal health risk of smoking could lead to both an immediate and planned behavioral control to quit smoking.

\section{Dual play of personal relevance and perceived susceptibility}

The findings of this study also showcase the importance of both personal relevance and perceived susceptibility in communicating health risks to individuals who have already engaged in unhealthy behaviors such as smoking. In other words, a health message that focused on one more than the other would end up being less effective. Previous studies indicated that in processing a fear appeal message, elaboration of the message as a result of high personal relevance could unexpectedly encourage message avoidance (e.g., Ruiter, Abraham, \& Kok, 2001). For instance, Liberman and Chaiken (1992) found that female coffee drinkers, compared to nondrinkers, were more likely to ignore the intervention message emphasizing the potential side effects of caffeine consumption. To prevent defensive information processing among those with high in personal relevance, therefore, perceived susceptibility should accompany personal relevance, as suggested by previous theoretical models of health information processing (e.g., EPPM; Witte, 1992, 1994) and the findings of the current study.

\footnotetext{
${ }^{2}$ A weak but significant correlation was found between perceived temporal distance and perceived relevance $(r=-.22, p<$ $.001)$. However, a confirmatory factor analysis revealed a significant chi-square difference between the unconstrained and constrained models of perceived temporal distance and perceived relevance $(t=2.19, p<.05)$, suggesting that the two constructs might present divergent validity (Zait \& Bertea, 2011).
} 


\section{Practical implications}

The findings of the current study provide useful practical implications for health professionals. Zhao et al. (2015) found that effective temporal framing was contingent on whether the recipients were present or future oriented (i.e., CFC; Strathman et al., 1994). For instance, present-oriented nonsmokers were more susceptible to the near-future frame, whereas future-oriented nonsmokers were more susceptible to the distant-future frame. However, individual traits such as CFC are difficult to identify or manipulate using communication stimuli. On the other hand, the current study found that a small tweak in the antismoking message (i.e., replacing a distantly perceived health risk [e.g., larynx cancer] with a proximally perceived risk [e.g., heart attack]) might trigger more vivid and concrete mental representations of the risk, resulting in higher levels of personal relevance and perceived susceptibility and greater intentions to quit smoking. The near-future and distant-future messages designed for the present study were based on current smokers' existing perceptions of the temporal distance to smoking-related health risks and, thus, expected to increase intention to quit among current smokers, regardless of CFC.

\section{Limitations and future research}

Among a few potential limitations of this study, the ecological validity of the findings should be considered. The participants in the present study received the stimulus antismoking messages via forced exposure in the context of an online experiment - a pragmatic limitation that might have decreased the realism of message exposure. Although feasibility (e.g., creating a realistic exposure environment specific to each participant) could still be an issue, future research should consider creating a setting to produce more naturalistic responses.

In assessing the effects of differently framed antismoking messages, this study primarily focused on recipients' perceived temporal distance to the smoking-related health risks presented in the messages and the resulting construal levels (i.e., concrete vs. abstract). However, the extent to which the recipients mentally represented the risks concretely or abstractly was not measured but only assumed, following the framework of CLT and methods used in previous studies (e.g., Nan et al., 2015; Zhao et al., 2015). Therefore, the findings of this study should be replicated using an extended model with construal level as a mediating variable.

Despite these potential limitations, the significance of the findings is compelling. They suggest a practical way to develop effective temporal framing: tapping into the preexisting perceptions of temporal distance held by current smokers with regard to various smoking-related health risks. Furthermore, the effectiveness of using temporal framing to target current smokers was empirically tested within a solid theoretical framework.

\section{References}

Amazon Mechanical Turk. (2015). Mechanical Turk is a marketplace for work. Retrieved from https://www.mturk.com/mturk/welcome

Beaudoin, C. E. (2002). Exploring antismoking ads: Appeals, themes, and consequences. Journal of Health Communication, 7, 123-137. doi:10.1080/10810730290088003

Berg, C. J., Ling, P. M., Hayes, R. B., Berg, E., Nollen, N., Nehl, E., Ahluwalia, J. S. (2012). Smoking frequency among current college student smokers: Distinguishing characteristics and factors related to readiness to quit smoking. Health Education Research, 27, 141-150. doi:10.1093/her/cyr106

Buhrmester, M., Kwang, T., \& Gosling, S. D. (2011). Amazon's Mechanical Turk: A new source of inexpensive, yet high-quality data? Perspectives on Psychological Science, 6, 3-5. doi:10.1177/ 1745691610393980

Center for Disease Control and Prevention. (2015). National adult tobacco survey (NATS). Retrieved from http://www.cdc.gov/tobacco/ data_statistics/surveys/nats/

Center for Disease Control and Prevention. (2016). Health effects of cigarette smoking. Retrieved from https://www.cdc.gov/tobacco/data_statistics/fact sheets/health effects/effects_cig_smoking/

Chaiken, S. (1987). The heuristic model of persuasion. In M. P. Zanna, J. M. Olson, \& C. P. Herman (Eds.), Social influence: The Ontario symposium (pp. 3-39). Hillsdale, NJ: Lawrence Erlbaum.

Chaiken, S., Liberman, A., \& Eagly, A. H. (1989). Heuristic and systematic information processing within and beyond the persuasion context. In J. S. Uleman \& J. A. Bargh (Eds.), Unintended thought (pp. 212252). New York, NY: Guilford. 
Chandran, S., \& Menon, G. (2004). When a day means more than a year: Effects of temporal framing on judgments of health risks. Journal of Consumer Research, 31, 375-389. doi:10.1086/422116

Conway, M. A., Meares, K., \& Standart, S. (2004). Images and goals. Memory, 12, 525-531. doi:10.1080/09658210444000151

D’Argembeau, A., \& van der Linden, M. (2006). Individual differences in the phenomenology of mental time travel: The effect of vivid visual imagery and emotion regulation strategies. Consciousness and Cognition, 15, 342-350. doi:10.1016/j.concog.2005.09.001

Dillard, A. J., McCaul, K. D., \& Klein, W. M. (2006). Unrealistic optimism in smokers: Implications for smoking myth endorsement and self-protective motivation. Journal of Health Communication, 11, 93- 102. doi:10.1080/10810730600637343

Dillard, J. P., Plotnick, C. A., Godbold, L. C., Freimuth, V. S., \& Edgar, T. (1996). The multiple affective outcomes of AIDS PSAs: Fear appeals do more than scare people. Communication Research, 23, 44-72. doi:10.1177/009365096023001002

Evans, R. I., Rozelle, R. M., Mittelmark, M. B., Hansen, W. B., Bane, A. L., \& Havis, J. (1978). Deterring the onset of smoking in children: Knowledge of immediate physiological effects and coping with peer pressure, media pressure, and parent modeling. Journal of Applied Social Psychology, 8, 126-135. doi:10.1111/ jasp.1978.8.issue-2

Friedman, M. (1996). Teen antismoking strategy focus groups: Summary report. Los Angeles, CA: Mara Friedman Research Management and Strategic Planning.

Fujita, K., Eyal, T., Chaiken, S., Trope, Y., \& Liberman, N. (2008). Influencing attitudes toward near and distant objects. Journal of Experimental Social Psychology, 44, 562-572. doi:10.1016/j.jesp.2007.10.005

Goldman, L. K., \& Glantz, S. A. (1998). Evaluation of antismoking advertising campaigns. Journal of the American Medical Association, 279, 772-777. doi:10.1001/jama.279.10.772

Ji, L.-J., Guo, T., Zhang, Z., \& Messervey, D. (2009). Looking into the past: Cultural differences in perception and representation of past information. Journal of Personality and Social Psychology, 96, 761- 769. doi:10.1037/a0014498

Kim, H. S., Bigman, C. A., Leader, A. E., Lerman, C., \& Cappella, J. N. (2012). Narrative health communication and behavior change: The influence of exemplars in the news on intention to quit smoking. Journal of Communication, 62, 473-492. doi:10.1111/jcom.2012.62. issue-3

Krieger, J. L., \& Sarge, M. A. (2013). A serial mediation model of message framing on intentions to receive the human papillomavirus vaccine: Revisiting the role of threat and efficacy perceptions. Health Communication, 28, 5-19. doi:10.1080/10410236.2012.734914

Lakoff, G. (2004). Don't think of an elephant: Know your values and frame the debate. White River Junction, VT: Chelsea Green Publishing.

Lakoff, G. (2010). Why it matters how we frame the environment. Environmental Communication, 4, 70 81. doi:10.1080/17524030903529749

Leshner, G., Bolls, P., \& Wise, K. (2011). Motivated processing of fear appeal and disgust images in televised anti-tobacco ads. Journal of Media Psychology, 23, 77-89.

Liberman, A., \& Chaiken, S. (1992). Defensive processing of personally relevant health messages. Personality and Social Psychology Bulletin, 18, 669-679. doi:10.1177/0146167292186002

Liberman, N., Sagristano, M. D., \& Trope, Y. (2002). The effect of temporal distance on level of mental construal. Journal of Experimental Social Psychology, 38, 523-534. doi:10.1016/S0022-1031(02)005358

MacKenzie, S. B., \& Lutz, R. J. (1989). An empirical examination of the structural antecedents of attitude toward the ad in an advertising pretest context. Journal of Marketing, 53, 48-65. doi:10.2307/1251413

Myers, L. B. (2014). Changing smokers' risk perceptions-For better or worse? Journal of Health Psychology, 19, 325-332. doi:10.1177/1359105312470154

Nan, X., Zhao, X., Yang, B., \& Iles, I. (2015). Effectiveness of cigarette warning labels: Examining the impact of graphics, message framing, and temporal framing. Health Communication, 30, 81-89. doi:10.1080/10410236.2013.841531

National Institutes of Health. (2007). Understanding cancer. NIH Curriculum Supplement Series [Internet]. Retrieved from http://www. ncbi.nlm.nih.gov/books/NBK20362/

National Institutes of Health. (2015). What is a heart attack? Retrieved from http://www.nhlbi.nih.gov/health/health-topics/topics/heartattack

Peters, G.-J. Y., Ruiter, R. A. C., \& Kok, G. (2013). Threatening communication: A critical re-analysis and a revised meta-analytic test of fear appeal theory. Health Psychology Review, 7, 8-31. doi:10.1080/17437199.2012.703527

Petty, R. E., \& Cacioppo, J. T. (1986). The elaboration likelihood model of persuasion. In L. Berkowitz (Ed.), Advances in experimental social psychology (pp. 123-205). New York, NY: Academic Press. 
Petty, R. E., Cacioppo, J. T., \& Goldman, R. (1981). Personal involvement as a determinant of argumentbased persuasion. Journal of Personality and Social Psychology, 41, 847-855. doi:10.1037/00223514.41.5.847

Rashtchian, C., Young, P., Hodosh, M., \& Hockenmaier, J. (2010). Collecting image annotations using Amazon's Mechanical Turk. CSLDAMT '10 Proceedings of the NAACL HLT 2010 Workshop on Creating Speech and Language Data with Amazon's Mechanical Turk, Los Angeles, CA.

Rogers, R. W. (1975). A protection motivation theory of fear appeals and attitude change. Journal of Psychology, 91, 93-114.

Ruiter, R. A. C., Abraham, C., \& Kok, G. (2001). Scary warnings and rational precautions: A review of the psychology of fear appeals. Psychology \& Health, 16, 613-630. doi:10.1080/08870440108405863

Ruiter, R. A. C., Kessels, L. T. E., Peters, G.-J. Y., \& Kok, G. (2014). Sixty years of fear appeal research: Current state of the evidence. International Journal of Psychology, 49, 63-70. doi:10.1002/ijop.12042

Scheufele, D. A., \& Tewksbury, D. (2007). Framing, agenda setting, and priming: The evolution of three media effects models. Journal of Communication, 57, 9-20.

Sinclair, J., \& Irani, T. (2005). Advocacy advertising for biotechnology. Journal of Advertising, 34, 59-73. doi:10.1080/00913367.2005.10639203

Slovic, P., Finucane, M. L., Peters, E., \& MacGregor, D. G. (2004). Risk as analysis and risk as feelings: Some thoughts about affect, reason, risk, and rationality. Risk Analysis, 24, 311-322. doi:10.1111/risk.2004.24.issue-2

Slovic, P., Finucane, M. L., Peters, E., \& MacGregor, D. G. (2005). Affect, risk, and decision making. Health Psychology, 24, S35-S40. doi:10.1037/0278-6133.24.4.S35

Slovic, P., Layman, M., Kraus, N., Flynn, J., Chalmers, J., \& Gesell, G. (1991). Perceived risk, stigma, and potential economic impacts of a high-level nuclear waste repository in Nevada. Risk Analysis, 11, 683696. doi:10.1111/risk.1991.11.issue-4

Staple, D. A., \& Velthuijsen, A. S. (1996). "Just as if it happens to me": The impact of vivid and self-relevant information on risk judgments. Journal of Social and Clinical Psychology, 15, 102-119. doi:10.1521/ jscp.1996.15.1.102

Strathman, A., Gleicher, F., Boninger, D. S., \& Edwards, C. S. (1994). The consideration of future consequences: Weighing immediate and distant outcomes of behavior. Journal of Personality and Social Psychology, 66, 742-752. doi:10.1037/0022-3514.66.4.742

Trope, Y., \& Liberman, N. (2000). Temporal construal and time-dependent changes in preference. Journal of Personality and Social Psychology, 79, 876-889. doi:10.1037/0022-3514.79.6.876

Trope, Y., \& Liberman, N. (2003). Temporal construal. Psychological Review, 110, 403-421. doi:10.1037/0033-295X.110.3.403

Trope, Y., \& Liberman, N. (2010). Construal-level theory of psychological distance. Psychological Review, $117,440-463$. doi:10.1037/a0018963

U.S. Department of Health and Human Services. (2014). The health consequences of smoking - 50 years of: A report of the Surgeon General. Retrieved from http://www.surgeongeneral.gov/library/ reports/50years-of-progress/

von Wagner, C., Semmler, C., Power, E., \& Good, A. (2010). What matters when deciding whether to participate in colorectal cancer screening? The moderating role of time perspective. Journal of Applied Biobehavioral Research, 15, 20-30. doi:10.1111/jabr.2010.15.issue-1

Weinstein, N. D., Marcus, S. E., \& Moser, R. P. (2005). Smokers' unrealistic optimism about their risk. Tobacco Control, 14, 55-59. doi:10.1136/tc.2004.008375

Witte, K. (1992). Putting the fear back into fear appeals: The extended parallel processing model. Communication Monographs, 59, 330-349. doi:10.1080/03637759209376276

Witte, K. (1994). Fear control and danger control: A test of the extended parallel processing model. Communication Monographs, 61, 113-134. doi:10.1080/03637759409376328

Witte, K., \& Allen, M. (2000). A meta-analysis of fear appeals: Implications for effective public health campaigns. Health Education Behavior, 27, 591-615.

Witte, K., Cameron, K. A., McKeon, J. K., \& Berkowitz, J. M. (1996). Predicting risk behaviors: Development and validation of a diagnostic scale. Journal of Health Communication, 1, 317-341. doi:10.1080/ 108107396127988

Wolburg, J. A. (2006). College students' responses to antismoking messages: Denial, defiance, and other boomerang effects. Journal of Consumer Affairs, 40, 294-323. doi:10.1111/j.1745-6606.2006.00059.x

Zaichkowsky, J. L. (1985). Measuring the involvement construct. Journal of Consumer Research, 12, 341352. doi:10.1086/jcr.1985.12.issue-3

Zait, A., \& Bertea, P. (2011). Methods for testing discriminant validity. Management \& Marketing, 9, $217-$ 224. 
Zajonc, R. B. (1980). Feeling and thinking: Preferences need no inferences. American Psychologist, 35, 151175. doi:10.1037/0003-066X.35.2.151

Zhao, X., Nan, X., Iles, I., \& Yang, B. (2015). Temporal framing and consideration of future consequences: Effects on smokers' and at-risk non-smokers' responses to cigarette health warning. Health Communication, 30, 175-185. doi:10.1080/10410236.2014.974122

Zillmann, D. (1999). Exemplification theory: Judging the whole by some of its parts. Media Psychology, 1, 69-94. doi:10.1207/s1532785xmep0101_5 


\section{Appendix}

\section{Full Path Model}

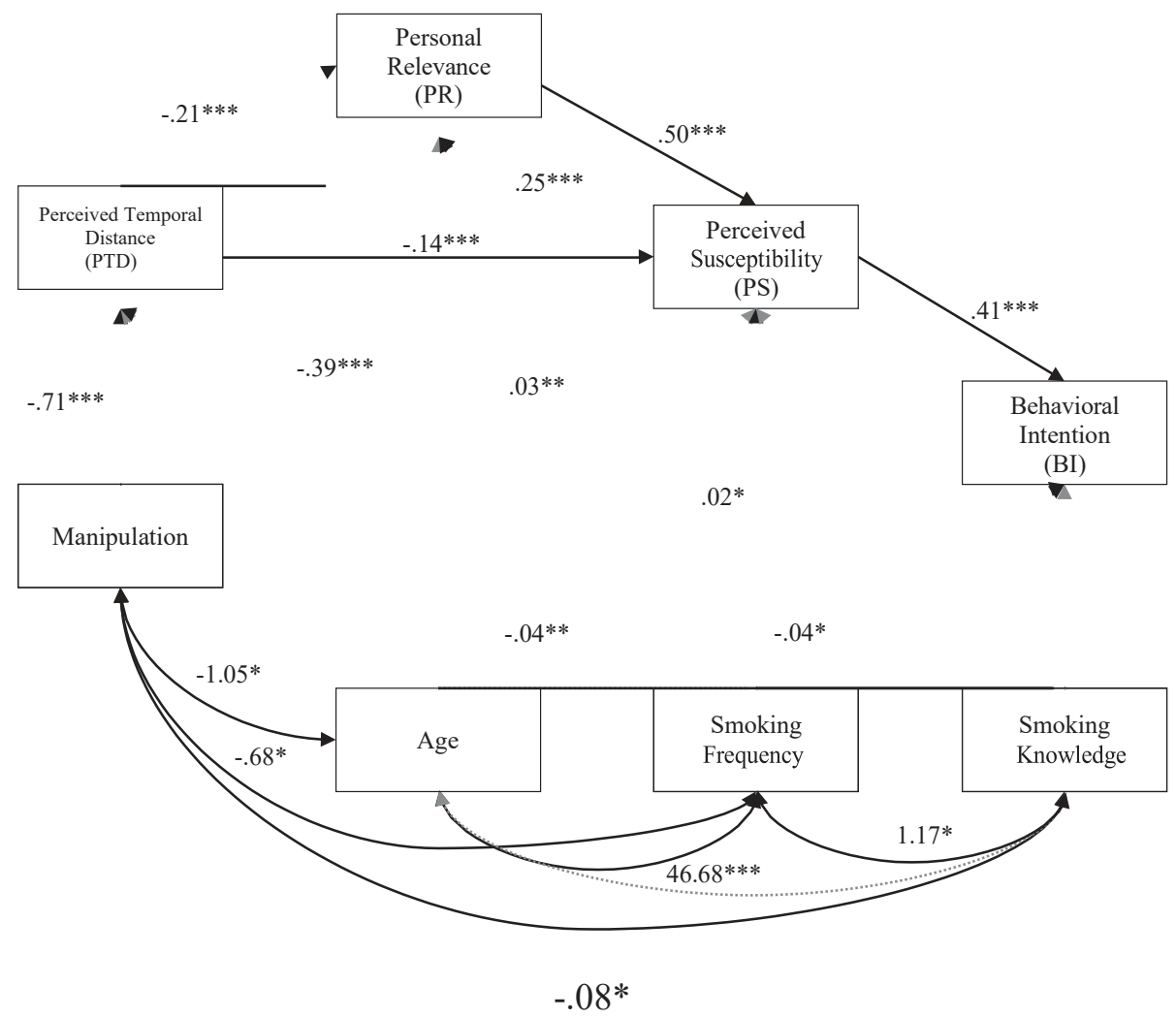

Note. Straight lines indicate significant paths, and broken lines indicate insignificant paths. Statistically significant at $* p<.05, * * p<.01$, or $* * * p<.001$ 
